\title{
Changes in microbial communities during phytoremediation of contaminated soil with phenanthrene
}

\author{
Diego D. Hariyo ${ }^{1}$ (D) Mario C. N. Saparrat ${ }^{2,3,4} \cdot$ Marcelo D. Barrera $^{5}$
}

Received: 6 November 2019 / Accepted: 27 May 2020 / Published online: 9 June 2020

(C) Sociedade Brasileira de Microbiologia 2020

\begin{abstract}
Although polycyclic aromatic hydrocarbons (PAHs) are environmental pollutants that affect negatively soils biology, several strategies lead to their removal such as the phytoremediation. In order to assess the potential of phytoremediation using "alfalfa" Medicago sativa as a strategy to reduce the phenanthrene on the soil, we analyzed the structure and dynamic of the microbial communities of a microcosm soil artificially contaminated with phenanthrene (2000 ppm), which was exposed to the plants. At different incubation times $(7,14,21,28,42$, and 56 days), a soil sample was taken from each microcosm and the residual amount of phenanthrene was quantified. Dehydrogenase activity and the count of fungi and bacteria were also estimated. Bacterial communities were characterized using PCR-DGGE, Shannon and Weaver's indexes, multivariate analysis, and rarefaction curves. It was found that phytoremediation treatment was associated with a higher richness and bacterial diversity compared with those on control soil. Although an OTUs (Operational Taxonomic Unit) succession over time was detected in both treatments, bacterial richness and diversity were conditioned by the phenanthrene concentration available and also dependent on the treatment, which were associated to different bacterial communities. In this study, phytoremediation treatment reduced the content of phenanthrene in the soil after 56 days to a $0.45 \%$ compared with the control treatment, which only reached to $4.25 \%$. This preliminary work suggests the promoting activity of "alfalfa" plants, through rhizodegradation, to remove in soil PAHs, as well as its relevance in the activation of different ecological processes mediated by soil microorganisms.
\end{abstract}

Keywords Rhizodegradation $\cdot$ PAHs $\cdot$ Bioremediation $\cdot$ Rhizosphere

Responsible Editor: Melissa Fontes Landell.

Diego D. Hariyo

diego.hariyo@agro.unlp.edu.ar

1 Facultad de Ciencias Agrarias y Forestales, UNLP, 60 y 119, 1900 La Plata, Argentina

2 Instituto de Fisiología Vegetal (INFIVE), UNLP, CCT, La Plata, CONICET, Diag. 113 y 61, CC 327, 1900 La Plata, Argentina

3 Instituto de Botánica Carlos Spegazzini, Facultad de Ciencias Naturales y Museo, Universidad Nacional de La Plata (UNLP), Comisión de Investigaciones Científicas de la Provincia de Buenos Aires (CIC), 53 \# 477, B1900AVJ La Plata, Argentina

4 Cátedra de Microbiología Agrícola, Facultad de Ciencias Agrarias y Forestales, UNLP, 60 y 119, 1900 La Plata, Argentina

5 LISEA, Facultad de Ciencias Agrarias y Forestales, UNLP, CC 31, 1900 La Plata, Argentina

\section{Introduction}

Aromatic polycyclic hydrocarbons (PAHs) are toxic compounds commonly found in soils and sediments of industrial areas, which are produced during the incomplete combustion of organic material through pyrolysis, being also abundant in fossil fuels [1]. They are electrochemically stable and can be extremely toxic, putting human and ecological health at risk. The physical and chemical properties of PAHs contribute to their persistence in the environment, both in their initial and chemically transformed forms [2].

The highest levels of soil contamination commonly occur in former sites of works for the extraction of hydrocarbons and where there are industrial activities that use oil and coal in their processes, such as the metallurgical industry, petroleum refining, and thermal power generation [3].

The presence of these substances in the soil constitutes a health hazard for those who have contact with contaminated sites. Because they are difficult to metabolize and discard, 
they are accumulated in some tissue, mainly in the adipose because they are soluble in lipids. They can cause cell mutation, resulting in different types of cancer [3].

Phenanthrene belongs to the chemical family of PAHs composed of three fused benzene rings [4]. At an environmental level, PAHs are toxic, commonly found in soils and sediments in industrial areas [5]. PAHs are electrochemically stable and can be extremely toxic, putting human health and the environment at risk [2].

In recent years, with the aim of eliminating hydrocarbons from contaminated soils, different economically attractive and environmentally friendly strategies have been developed compared with the available physical/chemical methods. All these procedures are based on the use of the metabolic capacities of microorganisms to degrade and/or detoxify contaminants $[6$, 7].

According to the US-EPA (United States Environmental Protection Agency) there are six basic techniques of phytoremediation; they are as follows:

Phytoextraction: It is the capture of metal ions by the roots of the plants and their accumulation in stems and leaves and then be harvested and treated.

Rhizofiltration: This procedure makes use of plant roots to decontaminate surface, underground, or liquid effluents contaminated with heavy metals and organic toxins, among other contaminants.

Phytostabilization: It is a technology for the physical, chemical, and biological stabilization of mining sites in the long term. The pollutants are absorbed by the roots of the plants, where they are accumulated in harmless forms, thus avoiding toxic effects on other living beings and preventing the underground layers from being affected. Phytodegradation: It is a process by which plants degrade organic compounds. The compounds are absorbed and metabolized. Very often, the metabolites they produce have phytohormones activity (accelerate plant growth). Plants that degrade explosive residues, chlorinated solvents and herbicides have been found.

Phytovolatilization: When trees absorb water contaminated with volatile organic compounds and eliminate them in the process of evapotranspiration through the leaves.

Rhizodegradation: Organic pollutants can biodegrade due to the intense microbiological activity that develops in the roots [8].

Previous studies have shown that the use of plants and their associated microorganisms to remedy PAH-contaminated soils could be an effective and sustainable solution to the problem [9-11]. Phytoremediation is a process based on the capacity of plants, which through their exudate roots stimulate and produce changes in the structure of the community, increasing the number of individuals and their diversity while promoting transformation/movement of PAHs in the area of influence of roots in contaminated soils [12-14]. However, current interventions do not always yield the expected results in field environments, which could be due to a lack of understanding of the multiple biological interactions occurring at the community level. Therefore, the study of the microbial communities and its interaction with the environment represents a promising challenge to improve bioremediation rates [8].

The structure of a community can basically be described by its wealth and diversity [15]. Although there are multiple causes why a community can change over time, in this study we will focus on those that we consider will be affected by our object of study: the disturbance caused by a xenobiotic pollutant [16] and the influence of the roots in the area of the rhizosphere $[17,18]$.

According to the above, richness and diversity in the rhizosphere could be expected as ecological and environmental conditions (concentration of phenanthrene, dehydrogenase activity and the number of fungi and bacteria) change over time [19].

Several studies document that the presence of PAH and its metabolites in the soil adversely affect the diversity of the community as a result of the toxic effect on microorganisms $[20,21]$. These authors have also shown that the diversity and richness of a contaminated soil could also decline due to the entry of a new carbon source and because of the change in the availability of phenanthrene in the soil, as a result of which are selected different consortia better adapted to the use of phenanthrene as a source of carbon in different degrees of availability $[16,22]$.

The objective of this work was the potential of phytoremediation as a strategy to reduce the phenanthrene on the soil and to analyze the effect of a phytoremediation treatment on the microbial community structure of a soil artificially contaminated with phenanthrene over time.

\section{Materials and methods}

Experiment in microcosms An experiment consisted of two treatments of soil contaminated with phenanthrene (2000 ppm), one implanted with Medicago sativa seedlings (F2000+R) and another control with contaminated soil (F2000). M. sativa is a species of herbaceous plant belonging to the family of Fabaceae or Leguminosae, perennifolia, erect to suberectate, being able to reach a size of $30-60 \mathrm{~cm}$ in height [23].

The terrariums were incubated under temperature controlled conditions $\left(25^{\circ} \mathrm{C}\right)$, according to the bibliography, the optimal range of growth for alfalfa growth [24], soil moisture $(20 \% \mathrm{w} / \mathrm{p})$, and photoperiod (14:10). The experiment used aliquots of a soil with no history of contamination 
corresponding to the surface material ( $>20 \mathrm{~cm}$ deep) taken from an area near the city of La Plata, Argentina, (Pereyra Iraola Park: 34-50' 49.6" S 58-07'09.1" W) with the following physicochemical properties: clay texture, $\mathrm{pH}$ of 5.8 to 5.9, $3.6 \%$ organic carbon, $6.21 \%$ organic matter, $0.296 \%$ total nitrogen, and $0.00042 \%$ of available phosphorus.

The soil sample obtained was processed in order to achieve a homogeneous mixture. The study units consisted of $7000 \mathrm{ml}$ plastic terrariums containing $2 \mathrm{~kg}$ of soil that was artificially contaminated with an acetonic solution of phenanthrene $(20 \%)$ and manually mixed with spatula, in order to achieve a final concentration in the soil of $2000 \mathrm{ppm}$. Subsequently, in the terrariums corresponding to the Treatment F2000R, M. sativa seedlings of 21 days of growth were applied at the rate of 1 seedling $/ 4 \mathrm{~cm}^{2}$, leaving as control other terrariums without plants. Three replicas were performed for each system.

At different incubation times $(7,14,21,28,42$, and 56 days), a soil sample of each terrarium ( $50 \mathrm{~g})$ was taken randomly corresponding to a depth of $2 \mathrm{~cm}$ considering the soil of the terrarium with seedlings as rhizospheric soil (F2000R) and the terrarium non-rhizospheric control (F2000), to analyze residual phenanthrene and different microbiological parameters.

Quantification of residual phenanthrene Residual phenanthrene of systems was quantified through US-EPA 8310 [8]. In a Soxhlet device, a filter paper envelope containing $25 \mathrm{~g}$ of a soil sample mixed with $25 \mathrm{~g}$ of anhydrous sodium sulfate and $200 \mathrm{ml}$ of ethyl acetate (Dorwil) was placed as an extraction solvent. The hydrocarbons were extracted for $6 \mathrm{~h}$. The concentration of extracts in ethyl acetate was estimated through high-pressure liquid chromatography in reverse phase (HPLC) following US-EPA 8310 protocol [8].

Microbiological parameter analysis In order to monitor an overall indicator of microbial metabolic activity present in soil, dehydrogenase activity was evaluated through the estimation of trichloride reduction from 2,3,5-triphenyl teliumtrazole (TTC) to triphenylforming, (TPF) following Thalman's protocol (1968) [25].

The quantification of fungi and bacteria was carried out following the Reasoner protocol (1985) [26], using plates containing the R2A medium for the count of cultivating heterotroph bacteria and plates with the RB medium for the fungal count. The plates were incubated at $20 \pm 2{ }^{\circ} \mathrm{C}$ for 10 days. The developed colonies were counted with magnifying glass to estimate colony-forming units (CFUs) per gram of dry soil.

The number of PAH-degrading microorganisms was also estimated in soil samples from each terrarium through the most probable number method (NMP) using 96-well polycubets, with each well containing $200 \mu$ of a liquid mineral solution implemented with a mixture of PAHs composed of phenanthrene $(0.5 \%)$, anthracene $(0.5 \%)$, fluorene $(0.5 \%)$, and dibenzothiophene $(0.5 \%)$ following the methodology reported by Wrenn [27]. In each vial, $20 \mu 1$ of different serial dilutions $(1 / 10)$ of soil were inoculated per octuplic, which after 2 weeks at $20^{\circ} \mathrm{C}$, was evaluated for the presence of color change (considered as positive) in response to the degradation of PAHs estimated use as a substrate by the soil-associated microbiota analyzed. The result was expressed as NMP method of treatment bacteria of $\mathrm{PAH} / \mathrm{g}$ of dry soil.

Bacterial community analysis using the PCR-DGGE technique Total DNA of the soil samples was extracted and purified from $1 \mathrm{~g}$ of sample. The extractions were made from the samples obtained from both treatments at 7, 14, 21, 28, 42, and 56 days from its implementation, using the E.Z.N.A. Soil DNA Commercial Kit (Omega Bio-tek, Norcross, GA, USA) following the protocol of the manufacturer Omega Bio-tek. Once the total DNA was extracted, a preserved portion of the 16S rRNA gene was amplified using the PCR protocol [28]. The 16S rRNA gene amps were obtained using the first 27 forward primer (50-AGAGTTGATCTGGCTCAG-30) and 1492 reverse primer (50TACGGCTACCTTAC GACTT-30) in a final reaction volume of $30 \mu$. The enzyme GoTaq DNA polymerase (Promega, Madison, WI) was used. The polymerase chain reaction (PCR) program consisted of an initial denaturation at $95^{\circ} \mathrm{C}$ per $2 \mathrm{~min}$, followed by 30 cycles of $95^{\circ} \mathrm{C}$ for $30 \mathrm{~s}, 72^{\circ} \mathrm{C}$ for $35 \mathrm{~s}$, and the final extension step that was performed at $72{ }^{\circ} \mathrm{C}$ for $5 \mathrm{~min}$. The thermocycler used was Eppendorf Mastercycler thermal cycler (Eppendorf, Hamburg, Germany).

PCR products were sown in gels of $6 \%$ polyacrylamide using a denaturing gradient 40-70\% (DGGE). Electrophoresis was performed in TAE $1 \mathrm{X}$ buffer in a DGGE-2401 apparatus (C.B.S Scientific Co., Del mar, CA, USA) at a temperature of $60^{\circ} \mathrm{C}$. A constant voltage of $100 \mathrm{~V}$ was applied for $16 \mathrm{~h}$ for the run. After electrophoresis, the gel was dyed for $1 \mathrm{~h}$ with SybrGold ${ }^{\circledR}$ (Invitrogen) to show the separate bands. The gel was observed by trans-illumination with UV light and digitized in a camera-CCD, saved as a .png file and then analyzed using the Gel Analyzer 2010 analysis software in order to obtain a primary matrix of data from the band patterns. The position of each band was considered as an OTU and its intensity used as an estimate of the number of individuals of the corresponding OUT.

Bacterial diversity was obtained through the Shannon and Weaver Index [29].

$\mathrm{H}^{\prime}=-\sum_{i=1}^{S}\left(P_{i} \times \log _{2} p_{i}\right)$

where

$S \quad$ Number of species $n_{\mathrm{i}}$ number of individuals of the species $i$ $n$ total number of individuals 
Each band was considered a species $(i)$, and the relative intensity of each band as its abundance $\left(n_{\mathrm{i}}\right)$. The sum of the area of the entire peaks of the densitometric curve was considered as the total number of individuals in the community (n) [30].

Statistical analysis In order to know whether the averages of the parameters analyzed residual phenanthrene concentration, dehydrogenase activity, fungal and bacteria CFU, and degrader NMP were significantly different, they were evaluated through an ANOVA test of repeated measures $(p<0.05)$.

The data corresponding to the estimation of the structure of the bacterial community were processed with the Biodiversity R Statistical Software, using a complement to the R commander for diversity calculations.

Rarefaction curves were carried out in order to compare two very different systems F2000 and F2000R, with different sampling intensities [31]. The average wealth values based on the rarefaction curve (smooth curve) were calculated using the Estimates program (Version 9.1.0), Copyright R. K. Colwell.

A principal component analysis (PCA) was performed to detect the relationships between species (OTUs) and the variables mentioned above by ordering cases on the composition of variables and a canonical correspondence analysis (CCA) to relate the composition of communities with environmental variables, humidity, and concentration of phenanthrene. Both techniques were carried out with XLStat 2018 Ecology software from the data obtained using the PCR-DGGE technique.

\section{Result}

After 56 days, the phytoremediation treatment showed an average value of $9 \mathrm{ppm}$ of residual phenanthrene easing compared with what was detected in the control system $85 \mathrm{ppm}$;

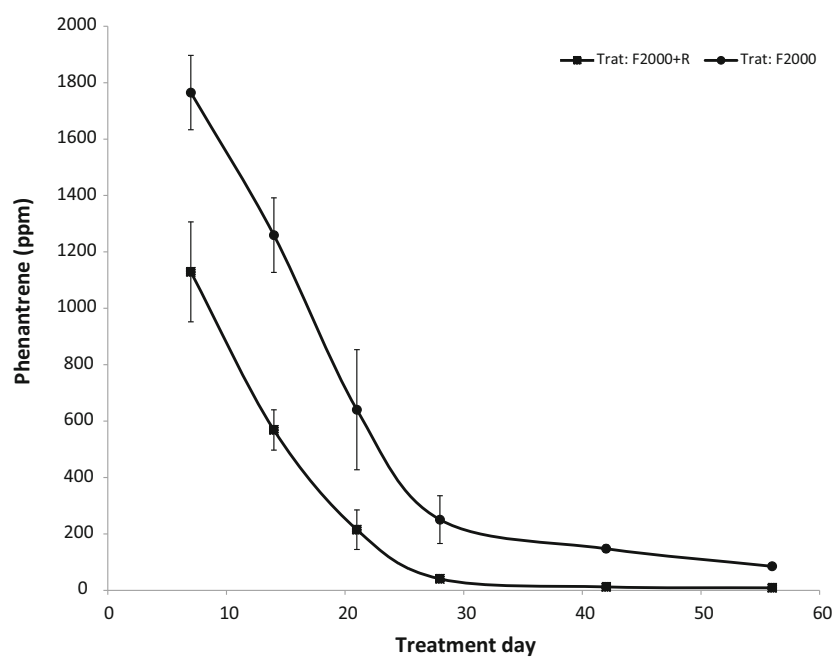

Fig. 1 Phenanthrene elimination kinetics (ppm) during treatment day $p<0.05$; (Fig. 1). However, only this rhizospheric effect of $M$. sativa was significant in the relative increase in removal of this PAH in the soil from the seventh day after the seedlings were applied to the soil with an average phenanthrene value of $1181 \mathrm{ppm}$ compared with the system $1798 \mathrm{ppm}(p<0.05)$.

Microbiological parameters Only 7 days after the experiment began, higher levels of dehydrogenase activity were detected in the system with $M$. sativa seedlings compared with the control system $(p<0.05)$ (Fig. 2a). However, at the other times evaluated, the activity of these enzymes in the system with $M$. sativa revealed significantly lower values to the control system $(p=0.05)$.

While the soil of the system containing the seedlings showed an amount of cultivable bacteria in an order of magnitude above the target estimate (Fig. 2b), the population of cultivable fungi revealed an opposite behavior since in the rhizospheric system, its number remained below the estimate in the control system (Fig. 2c). While this difference did not reach an order of magnitude, it remained throughout all treatment days.

The number of degrading microorganisms in the two systems had a fluctuating behavior, with the increased NMP of degraders in the first week of treatment and then declining in successive weeks (Fig. 2d).

Bacterial community structure using PCR-DGE A higher number of bands were observed in the F2000R system, a total of 114 bands in relation to the F2000 system where 46 bands were counted in total.

In successive measurement days, the F2000 system remained stable in terms of the number of bands ( 7 bands the first days of treatment and 6 bands at the end). However, the F2000R system had a completely different behavior, few bands were observed the first days of treatment ( 5 bands) and then increased in the successive days of treatment to a maximum of 34 bands on the 42nd day, to finish the 56th day with 26 bands. On the other hand, after identifying OTUs and following the onset and extinction of the OTUs at the time of treatment, a succession of OTUs was observed in both systems characterized by a one-way and sequential change in the relative dominance of species of the Community. The effect of the succession of different OTUs becomes more evident in the F2000R system, which has the greatest wealth. In this system, OTUs corresponding to bands $1,2,3,5$, and 7 seem to behave as a pioneer-opportunist taxa that dominates the community and are replaced by other OTUs $(8,9,10,11$, 12,13 , and 14), which, in turn, are additionally replaced by others $(22,23,24$ and 25$)$ more slowly, until reaching maturity or maximum complexity, although wealth does not increase. OTUs 4 and 6 remain throughout the treatment. 

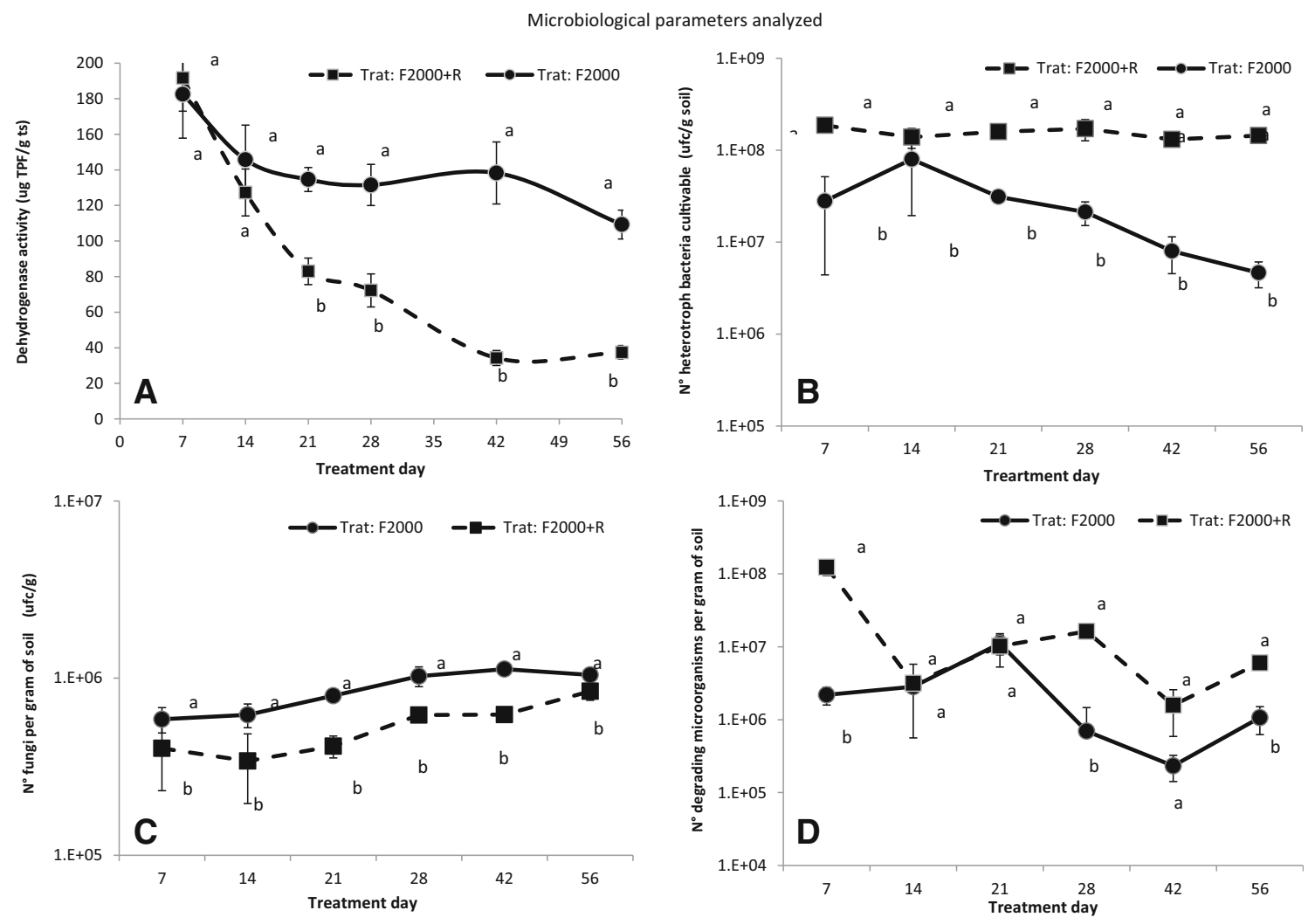

Fig. 2 Microbiological parameters analyzed in treatments based on time

Bacterial community structure The richness calculated through the rarefaction curves was significantly higher in the F2000R system $(86.85$ OTUs $\times 9.11, p<0.05)$ compared with the F2000 system $(16.35$ OTUs $\times 2.01)$. It was observed that significant difference between the two systems. In terms of diversity, the F2000 and F2000R systems exhibited different behavior over time. The F2000R system gradually increased as the treatment days increased (correlation coefficient R-0.82), while the F2000 system had a slight fluctuation in time, unrelated to the treatment day (correlation coefficient R-0.43). The F2000 system had higher rates of diversity at 7 days of treatment $\left(\mathrm{H}^{\prime} 1.82\right)$ compared to the F2000R system $\left(\mathrm{H}^{\prime} 1.41\right)$. However, from day 21, the H-diversity of the F2000R system begins to increase by outperforming the F2000 system, with final values at 56 days of $\mathrm{H}-1.69$ for the non-planted F2000 system and H-3.25 for the F2000R system.

Multivariate analysis The PCA explained on the F1 and F2 axes $83.16 \%$ of the total data variance (Fig. 3) and discriminate the samples for the F2000 and F2000R systems, with the F2000R system being 7 days apart from treatment that revealed a spatial pattern that differed notably compared with the rest of the samples in the F2000R system. While the first axis was related to wealth, diversity, residual concentration of phenanthrene, and dehydrogenase activity, the second axis

was associated with the number of fungi and cultured bacteria and hydrocarbon degraders. Diversity and richness variables are opposed in the graph to concentration of phenanthrene and dehydrogenase activity, showing its strong negative correlation $(-0.85)$. The amount of fungi (CFU) is also observed to be opposite on the chart to the amount of Bacteria (CFU) negative correlation $(-0.75)$.

The canonical correspondence analysis (CCA) uses the descriptive variable, specifically concentration of phenanthrene (F1 62.34\%), which explained the distribution of OTUs forming a well-defined group with OTUs 14, 36, 37, 31, 16, $30,27,46,19,39,10,20,11,40$, and 12 (Fig. 4).

It was observed that the F2000 and F2000R study system also influences the distribution of OTUs, forming welldelimited groups of OTUs $54,55,45,52$, and 53 related to the F2000 system, and 4, 36, 37, 31, 16, 30, 27, 48, 19, 39, 10, $20,11,40,12,33,42,35,24,26,22$, and 38 related to the F2000R system.

OTUs related to the high concentration of phenanthrene 48, 44, and 41 are observed. Opposite these appear OTUs where the concentration of phenanthrene is less than $16,19,23$, and 20.

The difference between the F2000 and F2000R systems is defined in the graph (Fig. 4), forming two groups to the right and left of the vertical axis, with the exception of the F2000(14) system to the left of the chart. 
Fig. 3 Principal component analysis (PCA)

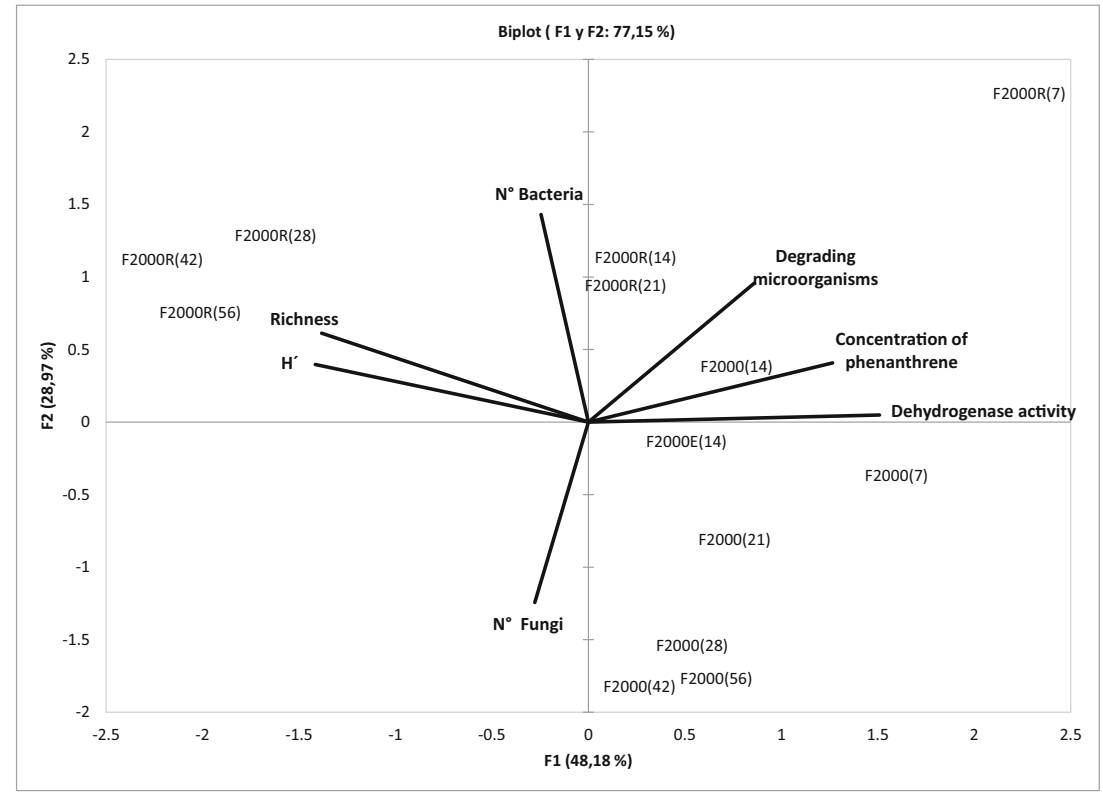

\section{Discussion}

Does phytoremediation have potential to be used as a technique to reduce the concentration of phenanthrene in contaminated soils? In accordance with the results obtained in terms of the kinetics of contaminant degradation in the F2000R system, it has been observed that plants, through their root exudates, stimulate and produce changes in the structure of the soil community, increasing the number of individuals and its diversity, while promoting PAH metabolism in the zone of influence of roots in contaminated soils $[14,16,17,32]$.
If the phenanthrene concentration values of the bare control soil (F2000) are compared with the soil subjected to phytoremediation (F2000R), significant differences $(p<0.05)$ are observed throughout the treatment with a final value of $9 \mathrm{ppm}$ for the F2000R system and $85 \mathrm{ppm}$ for the F2000 system. This result would indicate that phytoremediation does have the potential to be used as a technique in the remediation of contaminated soils.

Why some field tests do not give the expected results? If the success of the phytoremediation technique depends on high values of diversity, richness, number of individuals, and
Fig. 4 Canonical correspondence analysis (CCA) distribution of OTUs in relation to descriptive variables and study systems

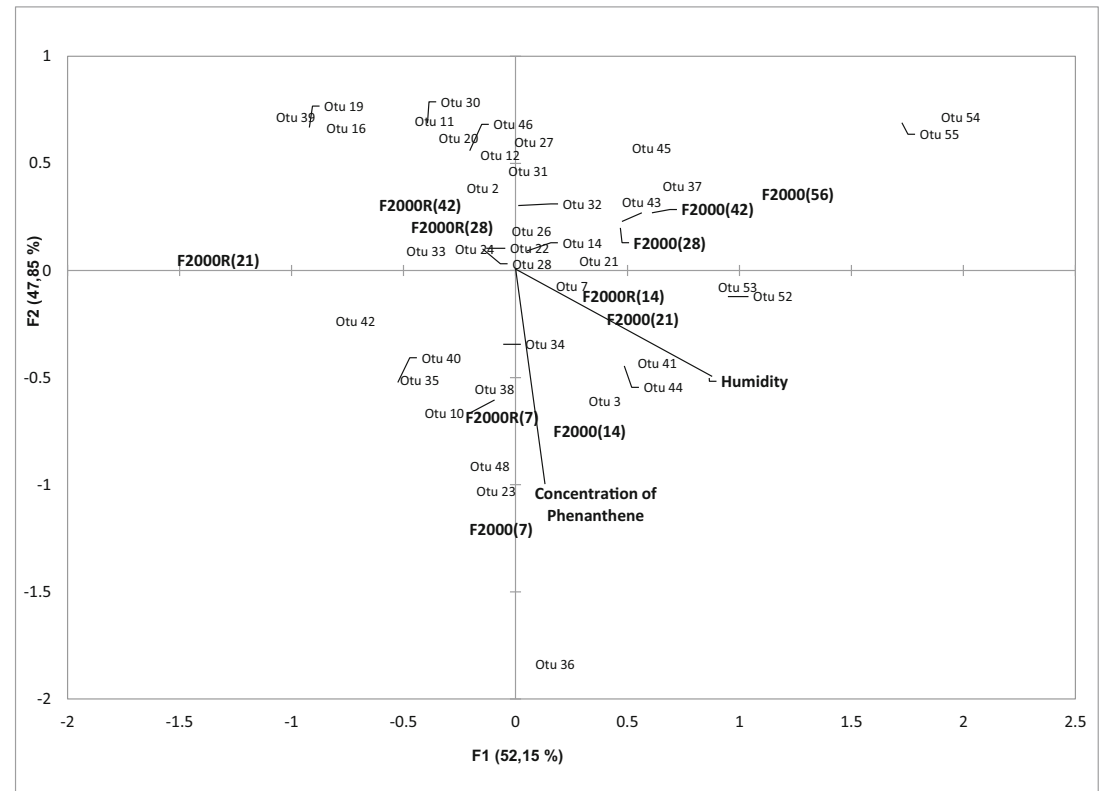


metabolic activity and they are key to the degradation of the pollutant [33], it would be expected that any change in these variables affect the effectiveness of the technique.

It is documented that during the phytoremediation process, large changes occur in the availability of the contaminant and the structure of the microbial community that affect the degradation kinetics of the contaminant [34]. As observed in the PCA, diversity and richness are negatively correlated with the concentration of phenanthrene (-0.85); therefore, changes at the community level are expected as the concentration of phenanthrene varies over time.

On the other hand, the disturbance caused by the pollutant can trigger changes at the community level, reducing the number of individuals and diversity $[35,36]$.

Another change at the community level detected in this work was a succession of OTUs over time. Specifically, a pattern similar to a secondary succession was detected, a process initiated by an event (for example, forest fires, harvesting, toxic spills, etc.) that disorganizes and reduces an already established ecosystem in a community with fewer species. [37]. Although there is an extensive literature on secondary successions in the soil [38-41], most of the studies are based on overexploited agricultural soils or forests after fires, and little has been studied in other systems, so it is interesting to detect these processes in contaminated soils.

\section{Could the original community influence the bottom line? The} particular conditions of the area to be remedied should be taken into account; the presence or absence of certain OTUs could play a key role in resistance to the pollutant and subsequent degradation [7].

In the CCA, the descriptive variable, specifically the concentration of phenanthrene (F1 62.34\%) explained the distribution of the OTUs, forming a well-defined antagonist group with well-differentiated OTUs, which could be explained by the tolerance of the different OTUs to the pollutant and the possibility of using them as a carbon source. Over time, the concentration of phenanthrene and its availability change when selecting the best adapted OTUs, generally the soil microorganisms that respond to disturbances caused by the input of matter and energy to the system with changes in the abundance of specific groups, as a consequence of the competencies in the exploitation of new substrates and the occupation of samples of species that do not adjust to the new conditions [42].

\section{Conclusion}

The work presented here suggests the importance of plants to promote PAH degradation and the existence of ecological processes to consider to improve existing phytoremediation techniques in terms of PAH residual values.
Among the ecological processes detected in this work, which should be taken into account since they influence the degradation of the pollutant, are the changes in values of diversity, richness, enzymatic activity, and succession of OTUs over time.

In this study, phytoremediation provided a significant reduction in the phenanthrene content in the soil after 56 days, with $0.45 \%$ residual compared with the control treatment $(4.25 \%)$.

Funding information The authors were financially supported by the Agencia Nacional de Promoción Científica y Tecnológica (PICT 20151620 to Saparrat M.C.N.), CONICET (PUE INFIVE), and UNLP, Argentina. Saparrat M.C.N. is a researcher from Consejo Nacional de Investigaciones Científicas y Tecnológicas (CONICET). Barrera, M.D., is a researcher from UNLP.

\section{Compliance with ethical standards}

Conflict of interest The authors declare that they have no conflict of interest.

\section{References}

1. Haritash A, Kaushik C (2009) Biodegradation aspects of polycyclic aromatic hydrocarbons (PAHs): a review. J Hazard Mater 169:1-15

2. Burchiel SW, Luster MI (2001) Signaling by environmental polycyclic aromatic hydrocarbons in human lymphocytes. Clin Immunol 98:2-10

3. Abdel-Shafy HI (2016) A review on polycyclic aromatic hydrocarbons: source, environmental impact, effect on human health and remediation. Egypt J Pet 25:107-123

4. Mallick S, Chatterjee S, Dutta TK (2007) A novel degradation pathway in the assimilation of phenanthrene by Staphylococcus sp. strain PN/Y via meta-cleavage of 2-hydroxy-1-naphthoic acid: formation of trans-2,3-dioxo-5-(2'-hydroxyphenyl)-pent-4-enoic acid. Microbiology 153:2104-2115

5. Hamdi H, Benzarti S, Aoyama I, Jedidi N (2012) Rehabilitation of degraded soils containing aged PAHs based on phytoremediation with alfalfa (Medicago sativa L.). Int Biodeterior Biodegradation 67:40-47

6. Kathi S, Khan AB (2011) Phytoremediation approaches to PAH contaminated soil. Indian J Sci Technol 4:56-63

7. Thijs S, Sillen W, Rineau F et al (2017) Towards a better understanding of plant-microbiome interactions to improve phytoremediation: engineering of the metaorganism. International Journal of Phytoremediation 19(1):23-38. https://doi.org/10.1080/ 15226514.2016.1216076

8. US EPA O (1986) US EPA, U.S. Environmental Protection Agency. U.S. EPA Method 8310, "Polynuclear aromatic hydrocarbons using HPLC," 1986. Available from: https://www.epa.gov/ hw-sw846/sw-846-test-method-8310-polynuclear-aromatichydrocarbons

9. Cui Y, Zhang W, Sun H, Wu WM, Zou X (2015) Polycyclic aromatic hydrocarbon accumulation in Phragmites australis grown on constructed wetland for sludge stabilization. J Residuals Sci Technol 12:215-220

10. Wei R, Ni J, Li X, Chen W, Yang Y (2017) Dissipation and phytoremediation of polycyclic aromatic hydrocarbons in freshly 
spiked and long-term field-contaminated soils. Environ Sci Pollut Res 24:7994-8003

11. Guo M, Gong Z, Miao R, Su D, Li X, Jia C, Zhuang J (2017) The influence of root exudates of maize and soybean on polycyclic aromatic hydrocarbons degradation and soil bacterial community structure. Ecol Eng 99:22-30

12. Smalla K, Wieland G, Buchner A, Zock A, Parzy J, Kaiser S, Roskot N, Heuer H, Berg G (2001) Bulk and rhizosphere soil bacterial communities studied by denaturing gradient gel electrophoresis: plant-dependent enrichment and seasonal shifts revealed. Appl Environ Microbiol 67:4742-4751

13. Siciliano SD, Germida JJ, Banks K, Greer CW (2003) Changes in microbial community composition and function during a polyaromatic hydrocarbon phytoremediation field trial. Appl Environ Microbiol 69:483-489

14. Badri DV, Loyola-Vargas VM, Broeckling CD, de-la-Peña C, Jasinski M, Santelia D, Martinoia E, Sumner LW, Banta LM, Stermitz F, Vivanco JM (2008) Altered profile of secondary metabolites in the root exudates of Arabidopsis ATP-binding cassette transporter mutants. Plant Physiol 146:762-771

15. Miller GT, Spoolman S (2011) Essentials of ecology, Cengage Learning

16. Chen J, Zhuang X, Xie H, Bai Z, Qi H, Zhang H (2007) Associated impact of inorganic fertilizers and pesticides on microbial communities in soils. World J Microbiol Biotechnol 23:23-29

17. Shi S, Richardson AE, O'Callaghan M et al (2011) Effects of selected root exudate components on soil bacterial communities. FEMS Microbiol Ecol 77:600-610

18. Liu C, Timper P, Ji P et al (2017) Influence of root exudates and soil on attachment of Pasteuria penetrans to Meloidogyne arenaria. $\mathrm{J}$ Nematol 49:304-310

19. Walker LR, Del Moral R (2003) Primary succession and ecosystem rehabilitation. Cambridge, UK, Cambridge University Press

20. Andreoni V, Cavalca L, Rao M et al (2004) Bacterial communities and enzyme activities of PAHs polluted soils. Chemosphere 57: $401-412$

21. Arias L, Bauzá J, Tobella J, Vila J, Grifoll M (2008) A microcosm system and an analytical protocol to assess PAH degradation and metabolite formation in soils. Biodegradation 19:425-434

22. Drenovsky R, Vo D, Graham K et al (2004) Soil water content and organic carbon availability are major determinants of soil microbial community composition. Microb Ecol 48:424-430

23. Linné CV (1753) Species plantarum: exhibentes plantas rite cognitas, ad genera relatas, cum differentiis specificis, nominibus trivialibus, synonymis selectis, locis natalibus, secundum systema sexuale digestas. Holmiae, Impensis Laurentii Salvii

24. Brown RH, Radcliffe DE (1986) A comparison of apparent photosynthesis in Sericea Lespedeza and Alfalfa ${ }^{1}$. Crop Sci 26. https:// doi.org/10.2135/cropsci1986.0011183X002600060027x

25. Thalmann A (1968) Zur Methodik der Bestimmung der DehydrogenaseaktivitAt im Boden mittels triphenytetra zoliumchlorid (TTC). Landwirtsch Forsch 21:249-258

26. Reasoner DJ, Geldreich EE (1985) A new medium for the enumeration and subculture of bacteria from potable water. Appl Environ Microbiol 49:1-7

27. Wrenn BA, Venosa AD (1996) Selective enumeration of aromatic and aliphatic hydrocarbon degrading bacteria by a most-probablenumber procedure. Can J Microbiol 42:252-258
28. Mullis K, Faloona F, Scharf S, Saiki R, Horn G, Erlich H (1986) Specific enzymatic amplification of DNA in vitro: the polymerase chain reaction. Cold Spring Harb Symp Quant Biol 51:263-273

29. Magurran AE (2004) Measuring biological diversity. Afr J Aquat Sci 29(2):106-108

30. Fromin N, Hamelin J, Tarnawski S, Roesti D, Jourdain-Miserez K, Forestier N, Teyssier-Cuvelle S, Gillet F, Aragno M, Rossi P (2002) Statistical analysis of denaturing gel electrophoresis (DGE) fingerprinting patterns. Environ Microbiol 4:634-643

31. Kraker-Castañeda C, Cóbar-Carranza A (2011) Uso de rarefacción para comparación de la riqueza de especies: el caso de las aves de sotobosque en la zona de influencia del Parque Nacional Laguna Lachuá, Guatemala. Naturaleza y Desarrollo 9:60-70

32. Thomas JC, Cable E, Dabkowski RT, Gargala S, McCall D, Pangrazzi G, Pierson A, Ripper M, Russell DK, Rugh CL (2013) Native Michigan plants stimulate soil microbial species changes and PAH remediation at a legacy steel mill. Int $\mathrm{J}$ Phytoremediation 15:5-23

33. Martin BC, George SJ, Price CA, Ryan MH, Tibbett M (2014) The role of root exuded low molecular weight organic anions in facilitating petroleum hydrocarbon degradation: current knowledge and future directions. Sci Total Environ 472:642-653

34. Wei R, Ni J, Guo L et al (2014) The effect of aging time on the distribution of pyrene in soil particle-size fractions. Geoderma 232: 19-23

35. Cravo-Laureau C, Hernandez-Raquet G, Vitte I, Jézéquel R, Bellet V, Godon JJ, Caumette P, Balaguer P, Duran R (2011) Role of environmental fluctuations and microbial diversity in degradation of hydrocarbons in contaminated sludge. Res Microbiol 162:888895

36. Chen X, Wei J, Liu X et al (2014) Effect of rhizodeposition on pyrene bioaccessibility and microbial structure in pyrene and pyrene-lead polluted soil. Chemosphere 97:92-97

37. Cook WM, Yao J, Foster BL, Holt RD, Patrick LB (2005) Secondary succession in an experimentally fragmented landscape: community patterns across space and time. Ecology 86:1267-1279

38. Maharning AR, Mills AA, Adl SM (2009) Soil community changes during secondary succession to naturalized grasslands. Appl Soil Ecol 41:137-147

39. Bokhorst S, Kardol P, Bellingham PJ, Kooyman RM, Richardson SJ, Schmidt S, Wardle DA (2017) Responses of communities of soil organisms and plants to soil aging at two contrasting long-term chronosequences. Soil Biol Biochem 106:69-79

40. Zhang C, Liu G, Xue S, Wang G (2016) Soil bacterial community dynamics reflect changes in plant community and soil properties during the secondary succession of abandoned farmland in the Loess Plateau. Soil Biol Biochem 97:40-49

41. Liao H, Zheng C, Li J, Long J (2018) Dynamics of soil microbial recovery from cropland to orchard along a 20-year chronosequence in a degraded karst ecosystem. Sci Total Environ 639:1051-1059

42. Wu T, Chellemi DO, Graham JH, Martin KJ, Rosskopf EN (2008) Comparison of soil bacterial communities under diverse agricultural land management and crop production practices. Microb Ecol 55: 293-310

Publisher's note Springer Nature remains neutral with regard to jurisdictional claims in published maps and institutional affiliations. 